\title{
Ludificando os Fundamentos de Computação Através de Aprendizagem Ativa
}

\author{
Tadeu Moreira de Classe ${ }^{1}$, Ronney Moreira Castro ${ }^{1}$
}

${ }^{1}$ Programa de Pós-Graduação em Informática (PPGI) - Departamento de Informática Aplicada (DIA) - Universidade Federal do Estado do Rio de Janeiro (UNIRIO) - Rio de Janeiro - RJ - Brasil

tadeu.classe@uniriotec.br, ronneymc@gmail.com

\begin{abstract}
There is a large number of failures and dropouts in the initial classes of courses in the computer area. Therefore, active learning comes with a strategy in an attempt to motivate and engage students by making them active in the learning process. This work reports the use of educational games, deceiving a basic computer discipline, seeking to improve student approval. During 4 periods, students' data on the practices used in the discipline were collected. Through the data analysis, it was possible to observe an improvement in learning and student satisfaction. In this way, it was realized that the active learning techniques used contributed to the improvement and motivation of students.
\end{abstract}

Resumo. Existe um grande número de reprovações e evasão em disciplinas iniciais de cursos da área de computação. Diante disso, a aprendizagem ativa surge como estratégia na tentativa de motivar e engajar os alunos, tornando-os ativos no processo de aprendizagem. Este trabalho relata o uso de jogos educacionais, ludificando uma disciplina básica de computação, buscando melhorar a aprovação dos alunos. Durante 4 periodos, foram coletados dados dos estudantes sobre as práticas usadas na disciplina. Por meio da análise dos dados, foi possivel observar uma melhoria no aprendizado e na satisfação dos estudantes. Desta maneira, percebeu-se que as técnicas de aprendizagem ativa utilizadas contribuíram para a melhora e motivação dos alunos.

\section{Introdução}

Em grande parte dos currículos de cursos superiores da área de Computação, nos períodos iniciais, estão presentes disciplinas básicas como algoritmos, programação e fundamentos de computação e sistemas [Zorzo et al., 2017]. Muitos alunos têm sua primeira experiência com os conceitos básicos de computação apenas ao iniciarem no curso superior, isso pode refletir em um grande número de reprovação, e, até mesmo, em desistência da disciplina e/ou do curso [Castro e Siqueira, 2019a]. Segundo o último Censo do Ensino Superior Brasileiro (INEP, 2019), a porcentagem de alunos concluintes em cursos da área de computação diminui com os anos: 31,8\% em 2016; 27,4\% em 2017 e $26,6 \%$ em 2018.

Em geral, o modelo de aula mais utilizado pelos professores nesta área é a expositiva devido ao fato de que muitos deles aprenderam desta maneira em sua formação [Castro e Siqueira, 2019b]. Este tipo de abordagem didática pode não ser a mais eficaz [Acharya et al., 2015]. Uma instituição de ensino superior, ao aceitar os alunos assume o compromisso com sua formação, o que implica em buscar alternativas educacionais e didáticas que se ajustem ao estilo de aprendizagem dos estudantes [Kessler et al., 2010].

Diante ao cenário de reprovações e evasão, estratégias didáticas vêm se destacando no intuito de prender a atenção dos alunos, dando-lhes protagonismo nas aulas, e mudando a forma de ensino e aprendizagem, como por exemplo: dinâmicas, 
seminários, sala de aula invertida, aprendizagem baseada em problemas, dentre outras [Castro e Siqueira, 2019a]. Este tipo de abordagem geralmente engloba a Aprendizagem Ativa (AA), que segundo Acharya et al. (2015), envolve técnicas que complementam as aulas e motivam os discentes a um estudo mais detalhado, engajando-os proporcionandolhes uma melhor retenção do conhecimento.

Há algum tempo que os jogos educacionais se destacam como recurso de apoio aos processos educacionais, permitindo a ludificação do ensino e aprendizagem. $\mathrm{O}$ uso destes recursos lúdicos representa uma oportunidade por estarem alinhados com o estilo de aprendizagem das gerações atuais, obtendo bons resultados em relação ao engajamento dos estudantes [Cardoso et al., 2019][Morais e Falcão, 2019]. Squire (2007) afirma que a aprendizagem usando brincadeiras e jogos é uma forma de engajar os alunos em atividades significativas, permitindo que eles assumam o protagonismo nas atividades, fazendo-os explorarem novas identidades, mundos e meios de aprendizado.

Desta forma, este trabalho relata a experiência de ludificação (jogos, gamificação, brincadeiras etc.) da disciplina de Fundamentos de Computação e Sistemas (FCS) dos cursos superiores de Tecnologia em Sistemas para Internet (TSI), e Análise e Desenvolvimento de Sistemas (ADS) de uma instituição da cidade de Juiz de Fora - MG, durante os anos de 2016 a 2019. Este relato visa demonstrar na prática como o uso de jogos educativos e seus elementos, contribuíram no engajamento, e, consequentemente, na melhoria da retenção de conhecimento, motivação, satisfação e aprovação dos alunos.

Após apresentar tal motivação e justificativa na introdução, a segunda seção do artigo apresenta a disciplina de FCS, relatando seus temas, as atividades ludificadas das aulas e uma breve análise da aprovação e da retenção dos alunos após a adoção de práticas baseadas em técnicas de AA. E as considerações finais são apresentadas na seção 3.

\section{Estratégias Lúdicas no Ensino de Fundamentos de Computação}

\subsection{Fundamentos de Computação e Sistemas}

A disciplina de Fundamentos de Computação e Sistemas (FCS) é lecionada no período inicial de TSI e ADS, sendo predominantemente teórica, abordando assuntos novos e complexos para a maioria dos ingressantes, como $^{1}$ : história da computação; grandezas computacionais; conversão de bases numéricas e operações com números binários; introdução a arquitetura de computadores; fundamentos de lógica e introdução à teoria da computação.

Esta disciplina foi introduzida nos cursos de TSI e ADS no ano de 2016, para que os alunos tivessem, mesmo que superficialmente, uma base sobre conceitos fundamentais da área computação e sistemas. Em seu $1^{\circ}$ semestre (2016/1), FCS foi ministrada de maneira $100 \%$ expositiva e os alunos avaliados apenas em provas bimestrais. Nesse cenário aconteceu um grande número de reprovações e desistências (Figura 4 - 2016/1). Devido a isso, a partir de 2016/2 até 2019/1², buscou-se alternativas lúdicas para as aulas, visando engajar os alunos, melhorando seu conhecimento e rendimento na disciplina.

Atividades de AA baseadas em jogos educacionais foram propostas, na tentativa de fazer com que os alunos ficassem imersos, assimilassem os novos conceitos e conseguissem por si ensinar uns aos outros. Assim, FCS passou a seguir a metodologia: 1) aula expositiva temática; 2) exercícios para casa; 3 ) atividades em formato de jogos educacionais (Tabela 1); e 4) encerramento (seminários e discussões). Em todas essas atividades, a iniciativa do aluno e seu engajamento eram traduzidos em pontos que eram acrescidos da nota de uma avaliação final com todos os assuntos, compondo a nota final.

\footnotetext{
${ }^{1}$ Assuntos extraídos do plano de ensino original da disciplina de FCS.

2 Oferta de FCS aos alunos: 2016/1, 2016/2, 2017/2, 2018/2, 2019/1. Em 2019/2 o docente se desligou da instituição por ser aprovado em concurso em IFES em regime de DE.
} 
Tabela 1. Técnicas de Aprendizagem Ativa - Atividades Lúdicas em FCS

\begin{tabular}{|c|c|c|}
\hline $\begin{array}{l}\text { Atividade } \\
\text { (Jogos) }\end{array}$ & Assunto & Descrição \\
\hline $\begin{array}{l}\text { Ludo } \\
\text { Numérico } \\
\text { (Figura } 1 \mathrm{~A})\end{array}$ & $\begin{array}{l}\text { Grandezas } \\
\text { Computacionais; } \\
\text { Conversão Entre } \\
\text { Bases } \\
\text { Numéricas }\end{array}$ & $\begin{array}{l}\text { O Ludo é um jogo de tabuleiro clássico onde os participantes precisam completar uma volta } \\
\text { no tabuleiro, jogando dados para vencerem. O Ludo Numérico é uma adaptação do } \\
\text { tradicional, no qual cada uma das casas do tabuleiro representa uma base numérica (binária, } \\
\text { octal e hexadecimal). A cada jogada, o jogador deve comprar uma carta, a qual é marcada } \\
\text { com um número. Os jogadores precisam converter este número para a base da casa onde seu } \\
\text { pino está. Em caso de erro de conversão, o jogador retorna à posição antes de jogar o dado. } \\
\text { Cada conversão tem } 1 \text { minuto para ser realizada, sendo penalizado como erro caso não seja } \\
\text { concluída nesse tempo. O jogo é jogado por } 4 \text { grupos de alunos. É responsabilidade de cada } \\
\text { um dos grupos, a cada rodada, confirmar se a conversão feita pelo grupo jogador está correta. }\end{array}$ \\
\hline $\begin{array}{l}\text { Caça ao } \\
\text { QRCode } \\
\text { (Figura } 1 B \text { ) }\end{array}$ & $\begin{array}{l}\text { Operações } \\
\text { Binárias e } \\
\text { Introdução à } \\
\text { Arquitetura de } \\
\text { Computadores }\end{array}$ & $\begin{array}{l}\text { Caça ao QRCode é um jogo no estilo caça ao tesouro, onde o jogador recebe uma pista } \\
\text { inicial, e sua resolução leva a outras pistas, até o tesouro. Neste caso, o jogo foi adaptado } \\
\text { com questões temáticas e as pistas são as respostas de cada uma das questões. A principal } \\
\text { ferramenta para "desvendar" as pistas são leitores de QRCode (smatphones). Assim, o grupo } \\
\text { de alunos recebe uma questão inicial, onde sua resposta leva a um determinado QRCode } \\
\text { espalhado pela sala de aula, a decodificação do QRCode origina uma próxima questão. Isso } \\
\text { ocorre até que os alunos cheguem corretamente a questão final (tesouro). }\end{array}$ \\
\hline $\begin{array}{l}\text { Maratona de } \\
\text { Circuitos } \\
\text { (Figura } 1 \mathrm{C})\end{array}$ & $\begin{array}{l}\text { Introdução à } \\
\text { Lógica }\end{array}$ & $\begin{array}{l}\text { Nos moldes de maratonas de programação usadas pela SBC, esta atividade consiste em } \\
\text { grupos de alunos tentando resolver problemas de lógica computacional, usando tabelas } \\
\text { verdade e operadores (portas) lógicos. Para isso os alunos utilizam simuladores de circuitos } \\
\text { digitais a fim resolver problemas baseados no mundo real (aprendizado baseado em } \\
\text { problemas), como: uma malharia possui } 4 \text { motores elétricos, porém sua rede elétrica } \\
\text { suporta apenas que } 2 \text { deles funcionem simultaneamente; crie um circuito digital que faça } \\
\text { disparar uma sirene de aviso quando } 3 \text { ou mais motores estiverem em funcionamento. Assim } \\
\text { os alunos conseguem exercitar na prática os conceitos relacionados ao assunto. }\end{array}$ \\
\hline $\begin{array}{l}\text { Maratona de } \\
\text { Autômatos }\end{array}$ & $\begin{array}{l}\text { Teoria da } \\
\text { Computação }\end{array}$ & $\begin{array}{l}\text { Assim como na maratona de circuitos, são entregues aos alunos diversos problemas } \\
\text { (linguagens e seus alfabetos) que devem ser executados em autômatos finitos } \\
\text { determinísticos. Os alunos devem implementar esses autômatos. Vence o grupo de alunos } \\
\text { que mais implementar autômatos de maneira correta ao final do tempo maratona. }\end{array}$ \\
\hline
\end{tabular}

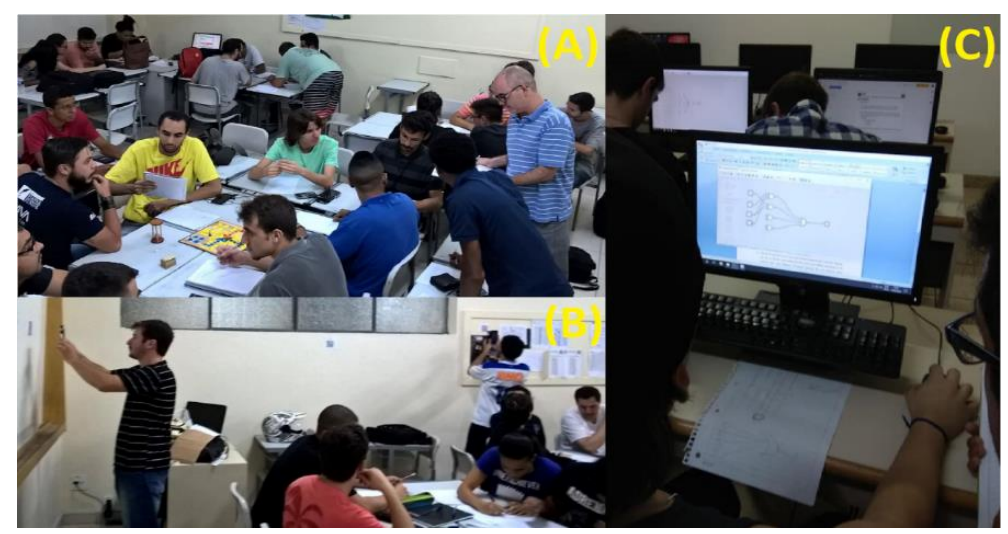

Figura 1. A) Ludo Numérico. B) Caça ao QRCode. C) Maratona de Circuitos.

\subsection{Após a Ludificação de FCS - Avaliação da Disciplina}

Durante os períodos em que a disciplina de FCS foi lecionada usando abordagens ludificadas baseadas no uso dos jogos educativos (2016/2 - 2017/2 - 2018/2 e 2019/1), os alunos eram convidados a responder uma pesquisa de opinião ${ }^{3}$ (não obrigatória) sobre a sua satisfação em relação a disciplina, professor e as atividades que foram usadas ${ }^{4}$.

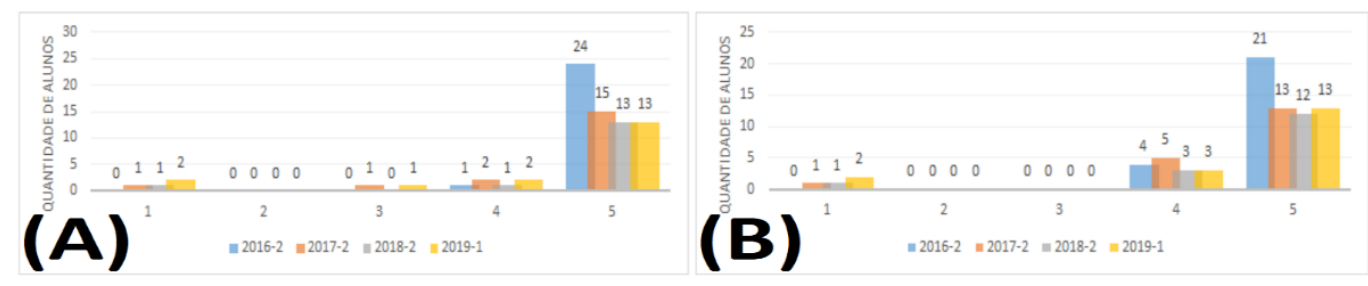

Figura 2. Satisfação dos Alunos: A) Com a Disciplina e B) Com o Docente.

A Figura 2 mostra as respostas dos alunos considerando a escala usada no questionário, que varia entre 1 (totalmente insatisfeito) e 5 (totalmente satisfeito). Além dos gráficos desenvolvidos para a análise dos dados, foi usado o teste chi-quadrado ${ }^{5}$ para

\footnotetext{
${ }^{3}$ Link para as respostas do questionário e análise dos dados: https://bit.ly/Wei2020CeC.

${ }^{4}$ Quantidade de Participantes do Questionário: 2016/2: 25; 2017/2: 19; 2018/2: 15; e 2019/1: 18.

${ }^{5}$ Considerando um nível de significância de alpha $=0,05$.
} 
verificar a significância das respostas dos alunos. De maneira geral, é possível perceber que a maioria dos alunos relatou a satisfação total com a disciplina (Figura $2 \mathrm{~A}-\chi^{2}=5,97$,

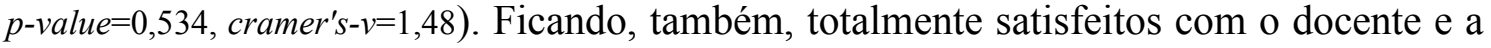

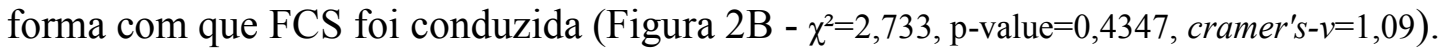

A consulta ainda investigou quais das técnicas de aprendizagem ativa usadas que os alunos mais gostaram. De acordo com as respostas apresentadas a partir na Figura 3, houve diferentes predileções entre os períodos avaliados. Em 2016/2 a preferência dos alunos foi pelos jogos das maratonas (80\%). Já em 2017/2 e 2018/2, a principal preferência girou em torno do Ludo Numérico (100\% e 69\%, respectivamente). E por último, em 2019/1, a preferência dos alunos foi pelos seminários (83\%).

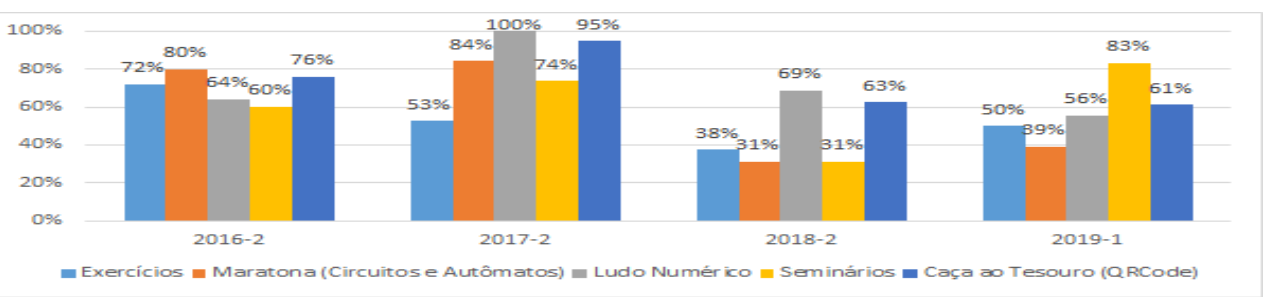

Figura 3. Preferência de Abordagens Ativas Usadas em FCS pelos Alunos.

O questionário ainda trazia a possibilidade de o aluno descrever suas considerações sobre a forma que FCS foi conduzida. A seguir são apresentadas a descrição de três alunos ${ }^{6}$ que avaliaram as abordagens usadas positivamente: Aluno X) "Gostei muito da forma como a disciplina foi abordada, diferente de todas que eu já tive. Sugiro que o professor continue com esse método, sempre buscando ensinar com métodos inovadores."; Aluno Y) "Acredito que a disciplina está ótima e que a forma que ela é dada, foge um pouco do padrão que é extremamente importante na minha opinião, pois acredito que os alunos ficam mais interessados. Acredito que o método funcionaria para qualquer matéria."; e Aluno Z) "Creio não há muito para melhorar, pois são muitas novidades e o professor procura estar junto com as expectativas da turma.".

Por último foi realizada a análise dos dados de aprovação dos alunos (contagem de aprovados e reprovados) entre os períodos onde era trabalhada de maneira tradicional (expositiva - 2016/1) e depois de FCS começar a ser trabalhada com técnicas de aprendizagem ativa (a partir de 2016/2 - Figura 4). É possível perceber uma mudança na relação da situação dos alunos em FCS, onde o percentual de aprovados é significativamente diferente (maior) entre os períodos da disciplina de FCS avaliados, tendo um tamanho de efeito médio $\left(\chi^{2}=54,813\right.$, $p$-value $=3,55 \mathrm{E}-11$, cramer' $\left.^{\prime}-v=0.31\right)$. Isso indica que o uso dos jogos educacionais (AA) foi positivo no nível de aprovação dos alunos.

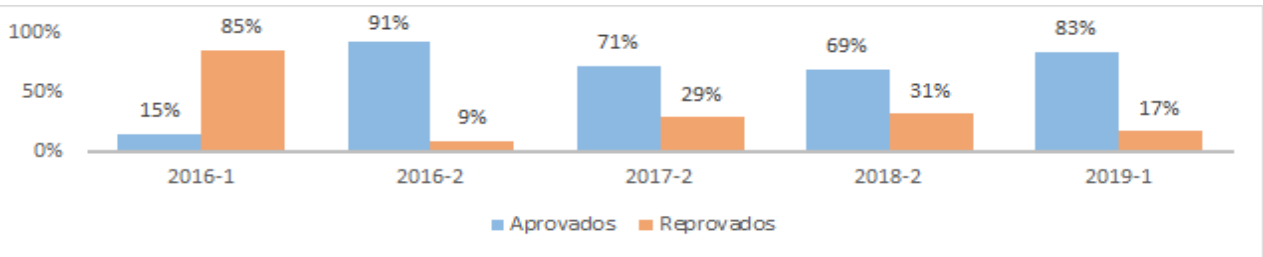

Figura 4. Relação entre aprovados e reprovados em FCS de 2016/1 até 2019/1.

\section{Considerações Finais}

Este trabalho trouxe o relato de experiência de uso de abordagens ativas nas aulas de Fundamentos de Computação e Sistemas, dos cursos TSI e ADS entre 2016 e 2019. A proposta se baseou na utilização de aulas lúdicas através de jogos educacionais para engajar e motivar os alunos, tornando-os ativos e protagonistas no processo de ensino e

\footnotetext{
${ }^{6}$ Foram coletadas muito mais descrições das percepções dos alunos, porém devido a limitação de espaço sua transcrição fica impossibilitada neste trabalho.
} 
aprendizado, e, em contrapartida, reduzir o número de reprovação e desistência no curso. Isso se deu, devido ao número preocupante de reprovados na disciplina, o professor se viu no desafio de melhorar a forma com que os assuntos eram abordados, migrando de aulas $100 \%$ expositivas para aulas mais dinâmicas e lúdicas.

Durante este período, os dados sobre alunos em relação a FCS foram coletados. Ao analisá-los foi possível perceber que houve uma diminuição na taxa de reprovação. Sendo relatado pelos alunos, que houve uma satisfação com a forma que a disciplina foi conduzida e com o docente. Contudo, ainda foi possível perceber que alguns alunos preferiam que a disciplina fosse trabalhada de forma tradicional (refletido na Figura 2 onde alguns apontaram insatisfação total).

Entende-se que este trabalho apresenta apenas o relato em do uso de AA em sala de aula, sendo que as mudanças nos índices de aprovação podem ter influência de outros fatores (motivação, trabalho, dedicação etc.) que não somente as práticas e jogos adotados na disciplina. Ainda, o engajamento e motivação dos alunos, também possa ter sido influenciado pela "novidade" na forma com que a disciplina foi conduzida, e na comparação com as outras aulas do curso, já que nas demais disciplinas do período foram lecionadas de maneira tradicional pelos demais docentes. Porém, isso é objeto de estudo e análise para trabalhos futuros.

Por fim, acredita-se que os resultados apresentados trazem indícios de que as técnicas de AA, traduzidas em jogos educacionais que permitiram ludificar a disciplina de FCS, contribuíram na satisfação, engajamento e melhoria do rendimento dos estudantes.

\section{Referências}

Acharya, S., Manohar, P., Wu, P. Y., Ansari, A. A., Schilling, W. W. (2015) "Integrated Active Learning Tools for Enhanced Pedagogy in a Software Engineering Course", In Journal Computers in Education, 7(2), p.17-28.

Cardoso, F., Otsuka, J., Tosta, M.S., Beder, D. (2019) "Estudo sobre dados relevantes para o acompanhamento de participações em jogos educacionais", In Simpósio Brasileiro de Informática na Educação (SBIE), 30(1), p. 922-931.

Castro, R.M.; Siqueira, S. (2019a) "Metodologias, Técnicas, Ambientes e Tecnologias Alternativas Utilizadas no Ensino de Algoritmos e Programação no Ensino Superior no Brasil." In Congresso Brasileiro de Informática na Educação, 8(1), p. 228-237.

Castro, R.M.; Siqueira, S. (2019b) "Técnicas Alternativas de Ensino (Aprendizagem Ativa) para Disciplinas da Computação: Um Mapeamento Sistemático no Contexto Brasil", In Workshop de Informática na Escola (WIE), 25(1), p.1409-1413.

INEP. (2019) "Censo da Educação Superior 2018, Divulgação de Resultados", Ministério da Educação.

Disponível

em: $<$ http://download.inep.gov.br/educacao_superior/censo_superior/documentos/2019/apresenta cao_censo_superior2018.pdf $>$. Acessado em: 17 de abril de 2020.

Kessler, M.C., Paula, C.G., Albé, M.H., Manzini, N., Barcellos, C., Carlson, R., Marcon, D., Kehl, C. (2010) "Impulsionando a aprendizagem na universidade por meio de jogos educativos digitais", In Simpósio Brasileiro de Informática na Educação, 1(1), p. 1-9.

Morais, D.C.S.; Falcão, T.P. (2019) "Abordagem Participativa no Desenvolvimento de Jogos Digitais Educacionais no Contexto Escolar", In Revista Brasileira de Informática na Educação (RBIE), 27(1), p.132-153.

Squire, K.D. (2007). "Games, learning, and society: Building a field", In Educational Technology, 47(5), p.51-55.

Zorzo, A. F., Nunes, D., Matos, E., Steinmacher, I., Leite, J., Araujo, R. M., Correia, R.,Martins, S. (2017), Referenciais de Formação para os Cursos de Graduação em Computação, Sociedade Brasileira de Computação (SBC). 